\title{
A Series Arrangement of Economizer - Evaporator Flat Solar Collectors as an Enhancement for Solar Steam Generator
}

\author{
Mahmmod Al-Saiydee ${ }^{1 *}$, Ali Alhamadani ${ }^{2}$, Waleed Allamy ${ }^{1}$ \\ 1 Engineering Technical College in Maysan, Electromechanical Engineering Department, Southern Technical \\ University, Basra, Iraq \\ 2 Engineering College, Mechanical Engineering Department, Wasit University, Wasit, Kut, Iraq \\ * Corresponding author's email: mahmmodaziz@stu.edu.iq
}

\begin{abstract}
Two flat solar collectors were designed and connected in series in order to achieve a moderately high outlet temperature. This high temperature is to be considered as the inlet temperature to a concentrated collector which is able of generating superheated steam. The first collector plays a role as a preheater; hence, it is called an economizer and the other plays a role as a temperature riser, thus it is called an evaporator. The economizer is a closed steel tank equipped with internal baffles distributed equally to ensure perfect circulation of water inside the tank. However, the evaporator consists of an array of vertical pipes connected to two horizontal manifolds (risers and headers) and bonded to a steel sheet. Both collectors are coated black with a granulated carbon layer and exposed to sun through two glass layers. Two water flow rates were applied at the evaporator $100 \mathrm{~L} / \mathrm{hr}$ and $200 \mathrm{~L} / \mathrm{hr}$. The result shows that a maximum outlet temperature of $73^{\circ} \mathrm{C}$ and a maximum efficiency of $82 \%$ at the beginning of the experiment and $55 \%$ by the end of experiment were achieved when the flow rate was $100 \mathrm{~L} / \mathrm{hr}$. In addition, the result shows that both collectors reached a situation where there was no useful gain in heat even, though the solar radiation beam still hits with considerable high intensity. This situation occurs when the heat losses increase. Both heat gain and heat lost were calculated and plotted for both collectors and at the two flow rates. In addition, an average value of solar radiation beam during the experiment was plotted.
\end{abstract}

Keywords: flat solar collector, solar radiation beam, heat gain, heat losses, operating efficiency

\section{INTRODUCTION}

The basic requirement of applications that use steam as working fluid or heat transfer medium, is to have dry steam or at least the steam with temperature sufficiently far from the saturation state. This implies long heating time and consequently greater fuel quantities to be burnt in order to super heat the steam and push its temperature high enough above the saturation state. Nevertheless, burning more fuel means high cost and excessive impact on the environment in terms of high percentage of greenhouse gases that results in the threatening global warming warming [Latake and Pawar, 2015., 2015; Wei Wu et al., 2017].

Accordingly, renewable energy is becoming a more and more promising source for future demands, being available free of charge and friendly to environment. Moreover, these sources of energy are available all over the world with varying percentages and intensity depends on the geographical location [Butturi et al., 2019].

In Iraq, the prevailing, abundant renewable energy is the solar energy as its location does not allow the practical exploit of wind, tidal or even geothermal energy because of its nature and weather [Miqdam \& Hussein, 2018]. For this reason, almost all studies that have been made in Iraq for producing electrical energy, distilled water and heating systems focused on solar energy as the only feasible source.

However, because of the drawbacks of solar energy, which are summarized as limited supply hours, restricted intensity of incident energy, its 
dependence on clear sky and its minimum requirements for wide and open area for installation, it is still an open issue which needs intensive studies and sophisticated technologies so that the solar energy can be optimized in quality and saved during night hours [Mofijur et al., 2019; Yuka \& Yuji, 2018; Reza et al., 2015].

Solar energy can be normally received as a thermal source through solar collectors. Many different designs for solar collectors have been so far proposed in order to increase the intensity of incident solar energy. The aim is to reflect the solar rays several times so that much energy can be gained. Another way is to focus the rays on a small area so that the intensity per certain square unit is denser and hence more heat is transferred to the absorbing surface. The application of the former procedure is called the flat solar collector while the application of the later proposal is called the concentrated solar collector [Kalogirou, 2004; Tian \& Zhao, 2013].

The incident area which is located at the center of concentrated collector is called the receiver, which is a small area that receives very intensive solar rays. Nevertheless, because of the small surface area of the receiver, the total amount of the heat received is small and thus it is lost immediately after the working fluid leaves the receiver [Alhamadani et al., 2018]. Such an issue can be overcome through preheating the working fluid to a certain high temperature before it passes through the receiver. This preheating can be achieved using flat collectors as these collectors offer larger absorbing area that enable the working fluid to absorb much heat, hence raising its temperature to the desired value [Amirgaliyev, et al, 2018; Saroj et al., 2019].

In this perspective, the thermal efficiency of a solar collector represents the most important parameter, as it decides how efficiently the collector is converting the incident solar energy into thermal energy which is transferred to the working fluid. Accordingly, over the years, many researchers have investigated different designs and materials in order to enhance the thermal efficiency of solar collector. Some researchers tried to replace the conventional working fluid (distilled water) with nanofluids. For instance, [Mohammed H. and Maysa S., 2018] studied the effect of Titanium Oxide $\left(\mathrm{TiO}_{2}\right)$ and $\mathrm{Zinc}$ Oxide $(\mathrm{ZnO})$ water-based nanofluids on the performance of solar flat plate collector. Three identical flat plate solar collectors were used; the working fluid in the first collector was pure water, while in the second collector, it was Titanium Oxide water-based nanofluid and in the third one-Zinc Oxide water-based nanofluid. The efficiency of the collector was found to be maximum over all values of temperature difference between inlet and ambience when a $0.2 \%$ volume fraction of Titanium Oxide was used with a maximum efficiency of $40 \%$, followed by the case of $0.6 \%$ volume fraction of Titanium Oxide. Finally, it was found that titanium oxide is characterized by more pronounced improvement in the performance of a solar flat plate collector. See also [Muhammad et al., 2019].

Other researchers tried to develop high selective coating for the absorbing plate and/or glazing so that much heat is absorbed and exchanged with the working fluid. [Ehrmann \& Reineke, 2012] developed a double glazing with a low-emitting (low-e) coating on the inner pane to improve the insulation of the transparent cover. The commercially available low-e glazing provides only insufficient solar transmittance for the application in thermal flat-plate collectors. Thus, they developed a sputter-deposited low e-coating system based on transparent conductive oxides which provides a high solar transmittance of $85 \%$ due to additional anti-reflective coatings and the use of low-iron glass substrates. The durability tests of the developed coating system show that their low e-coating system is well suitable even at high temperatures, humidity and condensation.

Nevertheless, there were many attempts to reduce the thermal losses by applying different insulation materials and double glass covers. In the work of [Giovannetti et al., 2014], the prototype exhibited an efficiency, which is $60 \%$ higher than that of a common single-glazed flat plate collector. By comparison with a commercially available double glazed flat plate collector with two non-selective AR-glass panes, the increase amounts to $23 \%$, mainly due to the selective coating of absorbing plate. The use of low-e glass with higher transmission and lower emissivity can provide for a further improvement: according to their simulations for the glass ITO max, a performance enhancement of $80 \%$ and $38 \%$ respectively is expected.

The current study focused on flat collectors as preheating system which is able to raise the working fluid temperature to a desired value. The working fluid used is distilled water with no additive materials. The proposal is to build two flat collectors with the same dimensions but with 
different absorbing surface area. One collector plays a role as an economizer and the other one as an evaporator. The terms come from the fact that a part of the working fluid leaving the first collector is pumped back to the main source; hence, it heats up the water enters the tank itself. The evaporator is a collector that has the working fluid circulating through pipes that are in direct contact with the heat source. Through the economizer, the working fluid is allowed to circulate inside a tank equipped with internal baffles. In turn, through the evaporator, the working fluid, which has just left the economizer, is allowed to be in contact with a larger surface area that is heated by the direct solar energy. Having passed these two flat collectors, the working fluid will have a temperature which is high enough to be a suitable inlet temperature of a concentrated collector.

\section{EXPERIMENT SETUP}

The experiment was run using two flat collectors connected in series via a water pump. Both collectors have the same dimensions. One collector is connected to the suction side of a water pump and the other is connected to the highpressure side of the pump. The first collector is called the economizer, while the other is called the evaporator. In order to control the flow rate through the evaporator, a valve was installed on the pipe that returns the flow to the water tank, while a flow meter was installed on the other pipe that is connected to the evaporator. See the schematic diagram in Figure 1.

The economizer is a tank made of galvanized steel $1 \mathrm{~mm}$ thick with the dimensions of $100 \mathrm{~cm}$ $\times 100 \mathrm{~cm} \times 5 \mathrm{~cm}$. The inside space of the tank is divided by baffles which are distributed in equidistance in order to force the water into flow in a zigzag movement, hence longer time for heat to transfer from the absorbing surface of the tank to the working fluid [Mahmmod A., 2000]. The upper surface of the tank is coated black with a granulated carbon layer in order to function as a selective absorbing surface [Zhonghua et al., 2014]. The layout of the baffles inside the tank is shown in Figure 2a.

The complete tank is installed inside a $110 \mathrm{~cm}$ $\times 110 \mathrm{~cm} \times 15 \mathrm{~cm}$ wooden case equipped with two glass covers (as glazing) and insulation around and beneath the tank. The glass used is $4 \mathrm{~mm}$ ordinary window glass [Ramadhani et al., 2014] and the insulation is $5 \mathrm{~cm}$ compressed polystyrene.

The evaporator is made of a galvanized steel plate $1 \mathrm{~mm}$ thick with the dimensions of $100 \mathrm{~cm}$ $\times 100 \mathrm{~cm}$ bonded to an array of 28 vertical copper pipes $1 \mathrm{~cm}$ outside diameter (called risers) connected to two horizontal manifolds, and copper pipes with $2.5 \mathrm{~cm}$ outside diameter, (called headers). The outside surfaces of the pipes along with the plate are coated black with a granulated

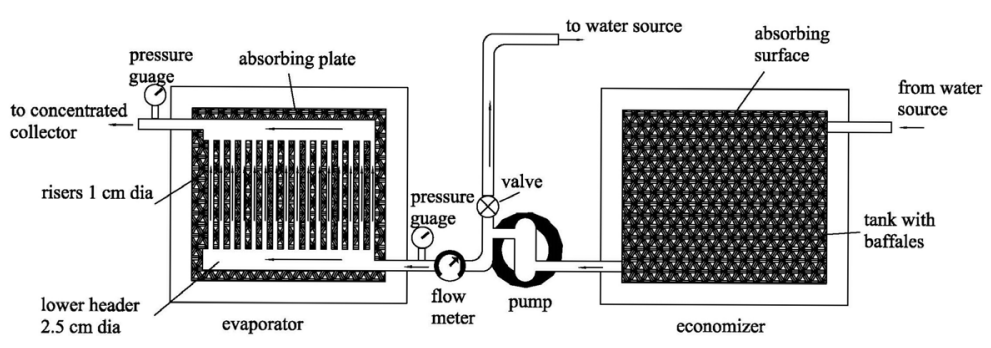

Fig. 1. Schematic diagram of experiment layout

a)

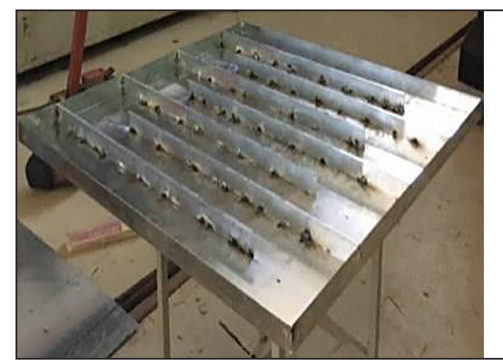

b)

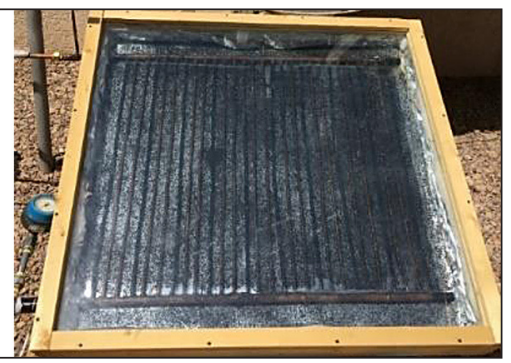

Fig. 2. (a) baffles inside the economizer, (b) the evaporator 
carbon layer in order to play as a selective absorbing surface. The complete arrangement is mounted inside a wooden case $110 \mathrm{~cm} \times 110 \mathrm{~cm}$ $\times 10 \mathrm{~cm}$ equipped with two glass covers and insulation layers around and beneath the plate. The glass used is $4 \mathrm{~mm}$ ordinary window glass and the insulation is $5 \mathrm{~cm}$ glass wool, see Figure $2 \mathrm{~b}$.

The experiment was run at different water flow rates which were measured by a flowmeter. The inlet and outlet temperatures of the water that flows in the economizer and evaporator were measured by a water thermometer. The absorbing surface temperature was measured using two thermocouples, one at the edge of the plate beneath the upper header and one in the center of the plate under one of the risers. The recorded absorbing surface temperature is the average numerical value of those two points. A radiometer was used to measure the solar radiation beam and a thermometer was used to measure the ambient temperature; these measuring instruments are shown in Figure 3.

It should be noticed that the economizer was installed on the suction side of the pump for several reasons among others; the first is to avoid the high-pressure flow of the pump that can cause swelling the tank and influences the circulation of water around the baffles. The second is to avoid cavity and vortexes inside the pump casing that could cause turbulences along the ongoing stream, hence affecting heat exchange within the economizer [Mihalić et al., 2014]. The longitude and latitude of the location where the experiment was run is $31.8379^{\circ} \mathrm{N}, 47.1421^{\circ} \mathrm{E}$.

\section{CALCULATION PROCEDURE}

As the aim was to preheat the water to a certain desired temperature, all inlet and outlet temperatures were measured by thermometers and thus all temperatures appearing in the following equations were considered known. Since there was no auxiliary heater used in the experiment, the only heat source considered was the direct incident solar energy which was measured by a radiometer. Moreover, the assumption of constant heat flux for heat transfer calculations was applicable.

Applying the assumption of steady state flow and referring to figure 4 , the heat gained by the water passing through economizer is expressed as follows [Holman, 2002].

$$
\dot{Q}_{e c o}=\dot{m}_{1} C_{P}\left(T_{2}-T_{1}\right)
$$

Where $\left(\dot{Q}_{\text {eco }}\right)$ is the useful heat gained by economizer, $\left(\dot{m}_{1}\right)$ is the mass flow rate passed through economizer, $C_{P}$ is the specific heat of water with constant pressure, $T_{1} \& T_{2}$ are the inlet and outlet temperatures of the water passed through the economizer.

It should be noticed that the value of the mass flow rate passing through the economizer is known from the sum of mass flow rate passed through the evaporator and the mass flow rate, which is returned to the water source. Since the flow through the pump is steady state, then the continuity equation is applicable, i.e.

$$
V_{2} \cdot A_{2}=V_{3} \cdot A_{3}
$$
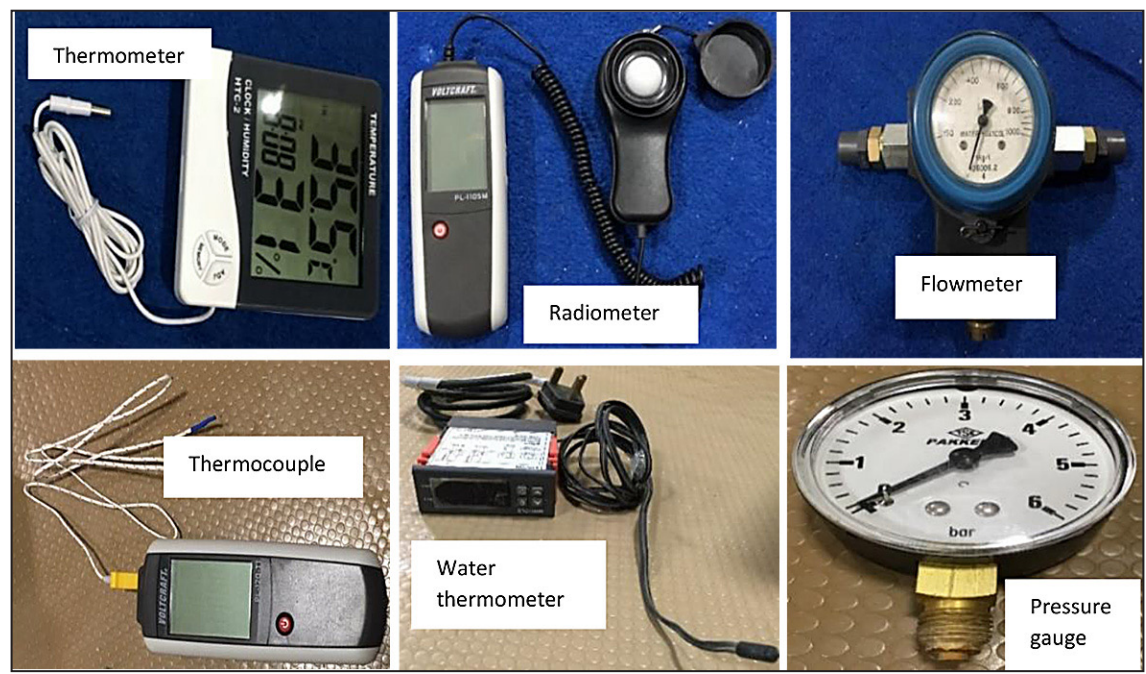

Fig. 3. Measuring instruments used in the experiment 


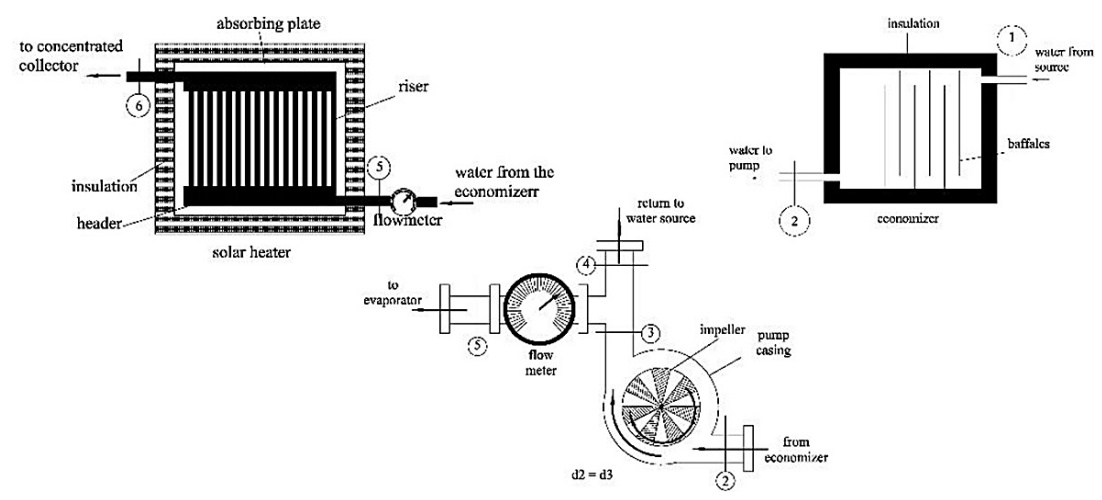

Fig. 4. The schematic drawing of the flow through the system

Where the subscripts refer to the inlet and outlet of the pump, $V$ is the velocity and $A$ is the flow area. Applying mass balance after the pump yields:

$$
\dot{m}_{2}=\dot{m}_{3}=\dot{m}_{4}+\dot{m}_{5}
$$

Where $\dot{m}_{2}$ is the mass flow rate entering the pump, $\dot{m}_{3}$ is the mass flow rate exiting the pump, $\dot{m}_{4}$ is the mass flow rate returns to the main tank and $\dot{m}_{5}$ is the mass flow rate enters the evaporator. The assumption of steady state flow is also applicable at the evaporator as there is no change in the water mass flow rate measured by the flow meter. Accordingly, the heat gained by the water flowing through the evaporator $\left(\dot{Q}_{\text {eva }}\right)$ is calculated as follows:

$$
\dot{Q}_{\text {eva }}=\dot{m}_{5} C_{P}\left(T_{6}-T_{5}\right)
$$

Where $\mathrm{T} 6$ is the outlet temperature of the evaporator.

The difference in diameters between risers and headers is to change the velocity of water within the evaporator and hence locally reduce the bulk flow pressure through the evaporator. This is expected to enhance the heat exchange between the hot surface and water [Gond et al., 2016] [Sunil et al., 2012].

The efficiency $(\eta)$ of both economizer and evaporator is calculated as follows:

$$
\eta=\frac{\dot{Q}_{e c o, e v a}}{I_{s}}
$$

Where $I_{s}$ represents the measured solar radiation beam in watts per square meters. The incident solar energy on the absorbing plate is $\dot{Q}_{S}$ which represents the solar radiation that was filtered by the two glass covers, i.e.:

$$
\dot{Q}_{s}=I_{s} \times \alpha_{1} \alpha_{2}
$$

Where $\alpha_{1} \& \alpha_{2}$ are the transmissivity of first and second glass cover respectively. The difference between $\dot{Q}_{S}$ and $\dot{Q}_{e c o, e v a}$ represents the heat lost through the glass covers, i.e.

$$
\dot{Q}_{\text {loss }}=\dot{Q}_{S}-\dot{Q}_{\text {eco,eva }}
$$

\section{RESULTS AND DISCUSSION}

The experiment was run for a period of six days during the period (12-20 August, 2018), six hours a day from 9:00 AM to 3:00 PM. The data were taken every 30 minutes which includes inlet and outlet temperatures for both the economizer and evaporator along with mass flow rate through the evaporator. In addition, the ambient temperature, humidity, and solar radiation beam were also recorded every 30 minutes.

Two mass flow rates were applied in the evaporator, i.e., 100 and 200 litters/hour, which corresponds to 0.0278 and $0.0556 \mathrm{~kg} / \mathrm{s}$, respectively. The experiment was run three days for each mass flow rate and then the average of the measured data was taken. As it was mentioned previously, the mass flow rate in economizer is considered constant and thus it was measured as a fixed value of $0.112 \mathrm{~kg} / \mathrm{s}(400 \mathrm{l} / \mathrm{hr})$.

The distribution of inlet and outlet temperatures of the economizer during experiment hours is shown in Figure 5. It is obvious that both curves are close to each other, which means less heat is gained in the economizer because of the high 


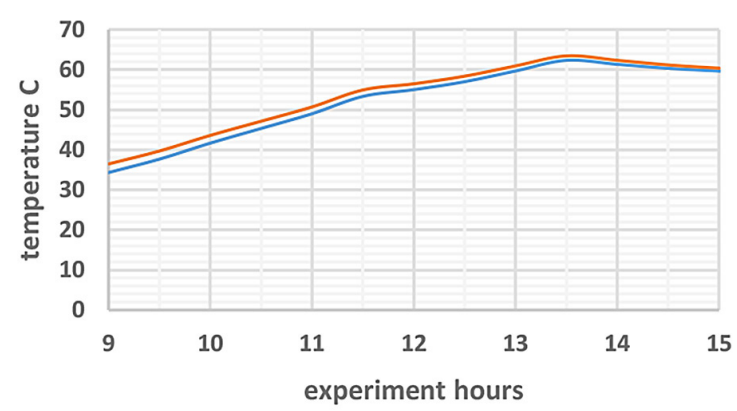

Fig. 5. The inlet and outlet temperatures of economizer

value of water flow rate $(400 \mathrm{l} / \mathrm{hr})$. Nevertheless, at least half of the water flow rate which leaves the economizer is returned back to the water source. Hence, the inlet temperature is increasing so that the situation when the economizer reaches a constant temperature difference is determined.

The inlet and outlet temperatures of the evaporator at the two different water flowrates 100 and 200 liters/hour are shown in figure 6.

It is clear that as the water flow rate increases, the difference in temperature between inlet and outlet becomes smaller because the time for exchanging heat is short. Inversely, both curves diverge from each other when the water flow rate decreases. The outlet temperature of economizer was taken as the inlet temperature for the evaporator and for both flow rates. In order to determine the behavior of the evaporator, the average temperature of six experiment days was considered instead of three days for each flow rate. The reasons are to avoid the fluctuations in the incident solar energy caused by the wind, the similarity in weather during the period when the experiment was run and also to ignore the heat loss through the pump as the two collectors are close to each other. This is well noticed from the similarity in behavior of temperature distribution for both the economizer and evaporator.
By applying equation 1 for both economizer and evaporator, the heat gained can be calculated. The heat gained by economizer and evaporator under two different flow rates is shown in fig. 7.

For both economizer and evaporator, the heat gain starts it maximum value at the first hour of experiment. This can be interpreted as both collectors were left uncovered over night after which they received enough solar energy that started to hit them almost two hours before the experiment was run. Accordingly, both collectors had reached their maximum temperatures before the experiment was run. Subsequently, the experiment was run fifteen minutes before 9:00 in order to avoid the first water flow from the evaporator which sometimes reached a mixture of water and steam (some short videos recorded during the first run hour are attached). It is obvious that the heat gained drops straightly forward as the inlet and outlet temperatures are getting closer to each other. Indeed, the heat gain was almost constant between 1:00 and 2:00 PM, as it can be seen in Figure 7. However, because of the movement of the sun towards sunset and the consequent reduction in incident solar energy, the heat gain continued to drop after 2:00 PM.

In order to evaluate the efficiency and heat losses from both collectors, the average value of solar radiation beam during the experiment is depicted in Figure 8. Three days were selected in order to have their average in the calculation of efficiency and heat losses. The selection takes in account the highest, lowest and the most common values of radiation beam.

The efficiency of economizer and evaporator is obtained from equation 4. Accordingly, the tendency of curve follows the one shown in Figure 7 for heat gain, see figure 9 which shows the efficiency of economizer and efficiency of evaporator under two different flow rates.

The heat lost from both economizer and evaporator can be calculated by applying equation 6 , a)

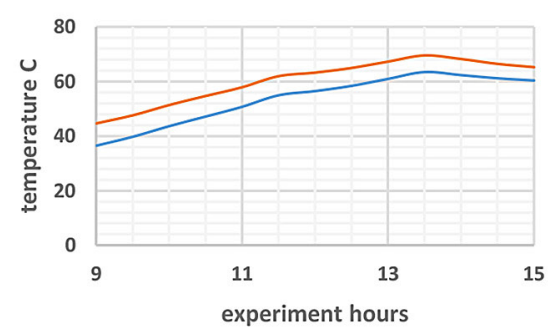

b)

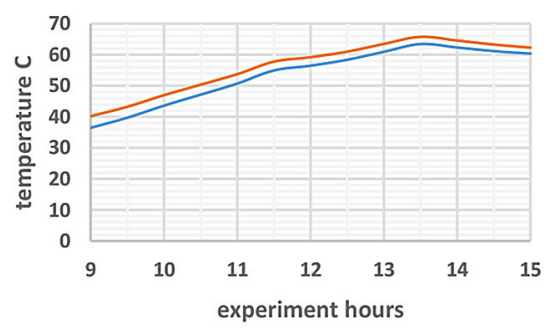

Fig. 6. The inlet and outlet temperatures of the evaporator at (a) 100 1/hr (b) 200 1/hr 


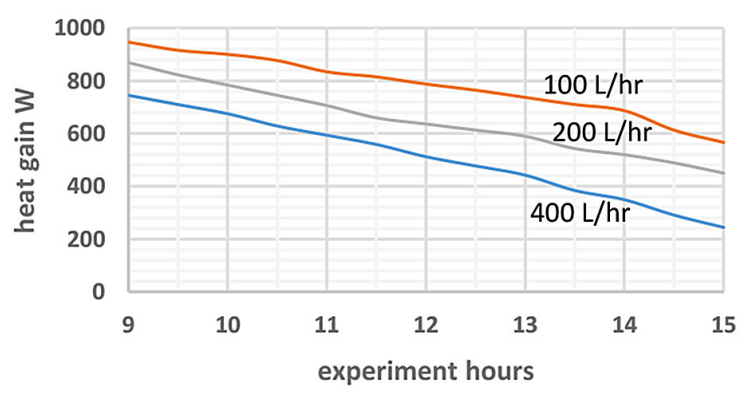

Fig. 7. The heat gained by economizer and evaporator under two different flow rates

which is shown in Figure 10. As it can be seen, the maximum heat lost occurs after midday when the water is no longer able to absorb any more heat even at low flow rate. Two factors have remarkable influence on the increase in heat lost first; the temperature of water passing in the pipes of the evaporators (risers and headers) is higher than the ambient temperature and hence heat is escaped from the absorbing surface to the ambience through the glass covers. Second, the incident solar energy after midday is less than its value before and at midday (see Fig. 8) which is unable to give any contribution to the temperature of the water passing through the evaporator.

As a comparison with [Walaa et al., 2018] in which a flat solar heater was manufactured and tested under two different flow rates $0.12 \mathrm{~L} / \mathrm{min}$ and $0.21 \mathrm{~L} / \mathrm{min}$ and the corresponding maximum outlet temperatures were $51^{\circ} \mathrm{C}$ and $49^{\circ} \mathrm{C}$ respectively. In our work, the highest outlet temperature is $73^{\circ} \mathrm{C}$ and $66^{\circ} \mathrm{C}$, the maximum efficiency reached is $86.19 \%$ and $66.24 \%$ and the maximum heat gain is $920 \mathrm{~W}$ and $860 \mathrm{~W}$ at 1.34 and $3.34 \mathrm{1} / \mathrm{min}$, respectively. Nevertheless, the evaporator was run with the efficiency between $70 \%$ and $50 \%$ for four hours, over the six hours of the experiment and this is a good performance for a flat plate solar heater.

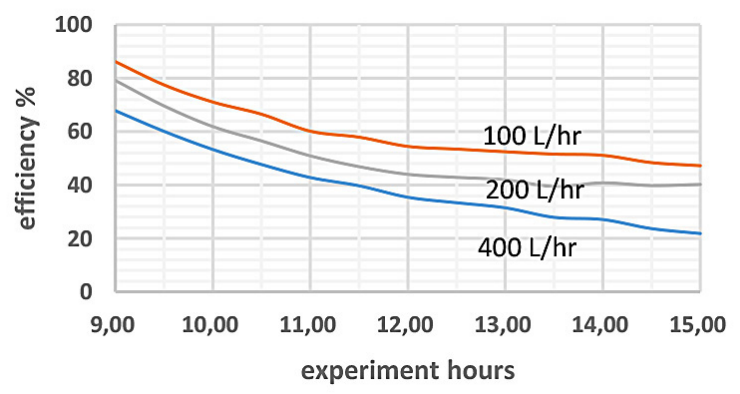

Fig. 9. The efficiency of economizer and evaporator under two different flow rates

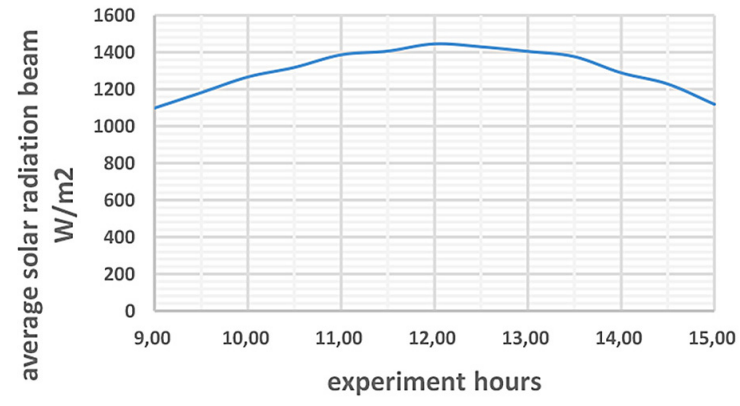

Fig. 8. The incident solar energy during the experiment period

Therefore, and for reason of comparison, the result of the current work is better in terms of outlet temperatures, heat gain and efficiency, taking into account the size of the collectors for both works are comparable.

\section{CONCLUSIONS}

Having shown the results of the experiment, it can be concluded that the series arrangement of economizer and evaporator has raised the temperature of the water within the water source from 34 at the morning to about 66 at midday. This gain in heat was accompanied by relatively high flow rate which sounds quite advantageous. In this context, the economizer can play dual functions; first as a preheater to the evaporator and second as a domestic solar water heater.

The evaporator has added about 10 degrees to the temperature received from economizer. Even though the flow rate is relatively low, it can be used as a reliable preheater to a concentrated solar collector. In this case, the water leaving evaporator will need about more 30 degrees in order to start evaporation. This rise in temperature can be achieved by the concentrated solar collector so that the steam produced is dry enough to condensate after leaving the receiver.

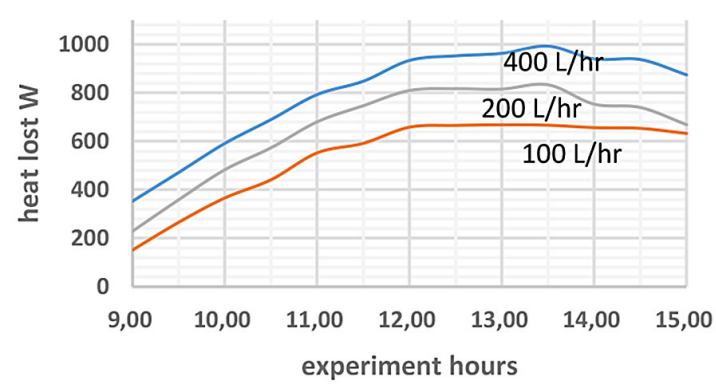

Fig. 10. Heat lost from economizer and evaporator under two different flow rates 


\section{REFERENCES}

1. Ali. A.F. Alhamadani, Abbas K. and Mahmmod A.M., 2018, Effect the Change of Absorber Length on Thermal Performance of Parabolic Dish Solar Collector, The Third International ScientificConference for Renewable Energy Applied Research / Southern Technical University, J.N.U.C., Vol. 6.

2. Amirgaliyev, et al, 2018, Calculation and Selection of Flat-Plate Solar Collector Geometric Parameters with Thermosiphon Circulation, Journal of Ecological Engineering, 19(6), 176-181

3. Butturi M.A., Lolli F., Sellitto M.A., Balugani E., Gamberini R., Rimini B., 2019, Renewable energy in eco-industrial parks and urban-industrial symbiosis: A literature review and a conceptual synthesis, Applied Energy, 255, 113825.

4. Ehrmann, N., Reineke-Koch R., 2012, selectively coated high efficiency glazing for solar-thermal flatplate collectors, Thin Solid Films 520, 4214-4218.

5. Giovannetti F., Föste S., Ehrmann N., Rockendorf G., 2014, High transmittance, low emissivity glass covers for flat plate collectors: Applications and performance, Solar Energy 104, 52-59.

6. Gond B. K., Mittal S., Prajapati P. and Khare R., 2016, Analysis of Solar Flat Plate Collector, international Journal of Research and Scientific Innovation (IJRSI) | Volume III, Issue VII.

7. Holman J. P., 2002 , Heat Transfer, McGraw Hill Company, 10th edition.

8. Kalogirou S.A., 2004, Solar thermal collectors and applications, Progress in Energy and Combustion Science, 30, 231-295.

9. Mahmmod A. M., 2000, The effect of using baffles on the performance of air solar heater having a continuous granulated carbon layer as an absorber, a master degree thesis, Gadjah University Press.

10. Mihalić, T., Guzović, Z. and Predin, A. , 2014, CFD flow analysis in the centrifugal vortex pump, International Journal of Numerical Methods for Heat \& Fluid Flow, 24(3), 545-562.

11. Miqdam T. and Hussein A, 2018, Generating Electricity Using Photovoltaic Solar Plants in Iraq, Springer, 35-45.

12. Mofijur M., Teuku Meurah Indra Mahlia, Arridina Susan Silitonga, Hwai Chyuan Ong, Mahyar Silakhori, Muhammad Heikal Hasan, Nandy Putra and S.M. Ashrafur Rahman, 2019 ,Phase Change Materials (PCM) for Solar Energy Usages and Storage:
An Overview, energies journal MPDI, 12, 3167.

13. Mohammed H. and Maysa S., 2018, Effect of Nanoparticles on the Performance of Solar Flat Plate Collectors, Journal of Ecological Engineering, 19(2), 1-7.

14. Muhammad M.J., Mohammad I. A., Sidik A.A.C., Yaziz M.N., Mamat Rezalmat and Najafi G., 2019, "The use of nanofluids for enhancing the thermal performance of stationary solar collectors: A review", Renewable and Sustainable Energy Reviews 63, 226-236.

15. Pooja T. Latake and Pooja Pawar, 2015, The Greenhouse Effect and Its Impacts on Environment, IJIRCT, 1(3), 333-337.

16. Ramadhani Bakari, Rwaichi J. A. Minja, Karoli N. Njau, 2014, Effect of Glass Thickness on Performance of Flat Plate Solar Collector for fruit drying, journal of energy, 10, Article ID 247287.

17. Reza Barzin, John J.J. Chen, Brent R. Young, Mohammed M. Farid, 2015, Application of PCM energy storage in combination with night ventilation for space cooling, Applied Energy, 158, 412-421.

18. Saroj Karki, Karl R. Haapala, Brian M. Fronk, 2019, Technical and economic feasibility of solar flat-plate collector thermal energy systems for small and medium manufacturers, Applied Energy, 254, 113649.

19. Sunil. K. Ghodke G. and Dr. Pattil K.N., 2012, Solar Flat Plate Collector Analysis, IOSR Journal of Engineering, 2(2), 207-213.

20. Tian Y., Zhao C.Y., 2013, A review of solar collectors and thermal energy storage in solar thermal applications, Applied Energy, 104, 538-553.

21. Walaa M.H., Ali T.S., Hasan A.J., Tayser A.G., Abdul Amir H.K. and Ahmed A.A., 2018, case study on solar water heating for flat plate collector, case studies in thermal engineering, 12, 666-671.

22. Wei Wu, Po-Han Wang, Duu-Jong Lee, Jo-Shu Chang, 2017, Global optimization of microalgaeto-biodiesel chains with integrated cogasification combined cycle systems based on greenhouse gas emissions reductions, Applied Energy, 197, 63-82.

23. Yuka Kusama, Yuji Ishidoya, 2018, Study on a tankless solar heating system using phase-change material plaster, Building and Environment, 127, 256-267.

24. Zhonghua Chena, Zain A and Bostrom T., 2014, Simulation of Anti-Reflection Coated Carbonaceous Spectrally Selective Absorber, Renewable Energy Research Conference, RERC. 